\title{
Clinical Application of Esophageal High-resolution Manometry in the Diagnosis of Esophageal Motility Disorders
}

\author{
Froukje B van Hoeij and Albert J Bredenoord* \\ Department of Gastroenterology and Hepatology, Academic Medical Center, University of Amsterdam, Amsterdam, The Netherlands
}

Esophageal high-resolution manometry (HRM) is replacing conventional manometry in the clinical evaluation of patients with esophageal symptoms, especially dysphagia. The introduction of HRM gave rise to new objective metrics and recognizable patterns of esophageal motor function, requiring a new classification scheme: the Chicago classification. HRM measurements are more detailed and more easily performed compared to conventional manometry. The visual presentation of acquired data improved the analysis and interpretation of esophageal motor function. This led to a more sensitive, accurate, and objective analysis of esophageal motility. In this review we discuss how HRM changed the way we define and categorize esophageal motility disorders. Moreover, we discuss the clinical applications of HRM for each esophageal motility disorder separately.

(J Neurogastroenterol Motil 2016;22:6-13)

\section{Key Words}

Diagnosis; Esophageal achalasia; Esophageal motility disorders; Esophageal spasm, diffuse

\section{Introduction}

Disordered esophageal motor function can be an underlying cause of dysphagia and chest pain. Esophageal manometry is the gold standard for assessing esophageal motility. Ever since the first concept was invented in the 1950s, ${ }^{1}$ continuous technical modifications have improved the measuring techniques. ${ }^{2}$ The first pressure recordings of the esophagus were performed using water-perfused catheters with one to a few side-holes, after which 4-8 side-holes became common. Measuring the pressure of the lower esophageal sphincter (LES) was difficult, because the LES tends to shift upwards during swallows, displacing a focal point sensor away from the high pressure zone. The convention at the time was to pull a focal sensor repeatedly through the sphincter. In 1977, the Dent sleeve sensor catheter was introduced, in which a 6-cm sleeve sensor was added to continuously measure the LES pressure. ${ }^{3,4}$ By the 1990s, high-resolution manometry (HRM) was introduced, which had an increased number of pressure sensors thereby decreasing the spacing between the respective sensors to $1-\mathrm{cm}$ intervals. ${ }^{5}$ The pioneers were Ray Clouse and Geoff Hebbard. ${ }^{6}$ This made it possible to measure the pressure pattern throughout the entire length of the esophagus with each swallow, from upper esophageal sphincter (UES) to LES, providing a complete depiction of esophageal motor function. ${ }^{7,8}$ Furthermore, the short interval between sensors allowed the software to interpolate pressure values between sen-

Received: October 27, 2015 Revised: November 19, 2015 Accepted: November 22, 2015

(.) This is an Open Access article distributed under the terms of the Creative Commons Attribution Non-Commercial License (http://creativecommons. org/licenses/by-nc/4.0) which permits unrestricted non-commercial use, distribution, and reproduction in any medium, provided the original work is properly cited.

*Correspondence: Albert J Bredenoord, MD, PhD Department of Gastroenterology and Hepatology, Academic Medical Center Amsterdam, Meibergdreef 9, 1105 AZ Amsterdam, The Netherlands

Tel: +31-205661745, Fax: +31-205669478, E-mail: a.j.bredenoord@amc.uva.nl 


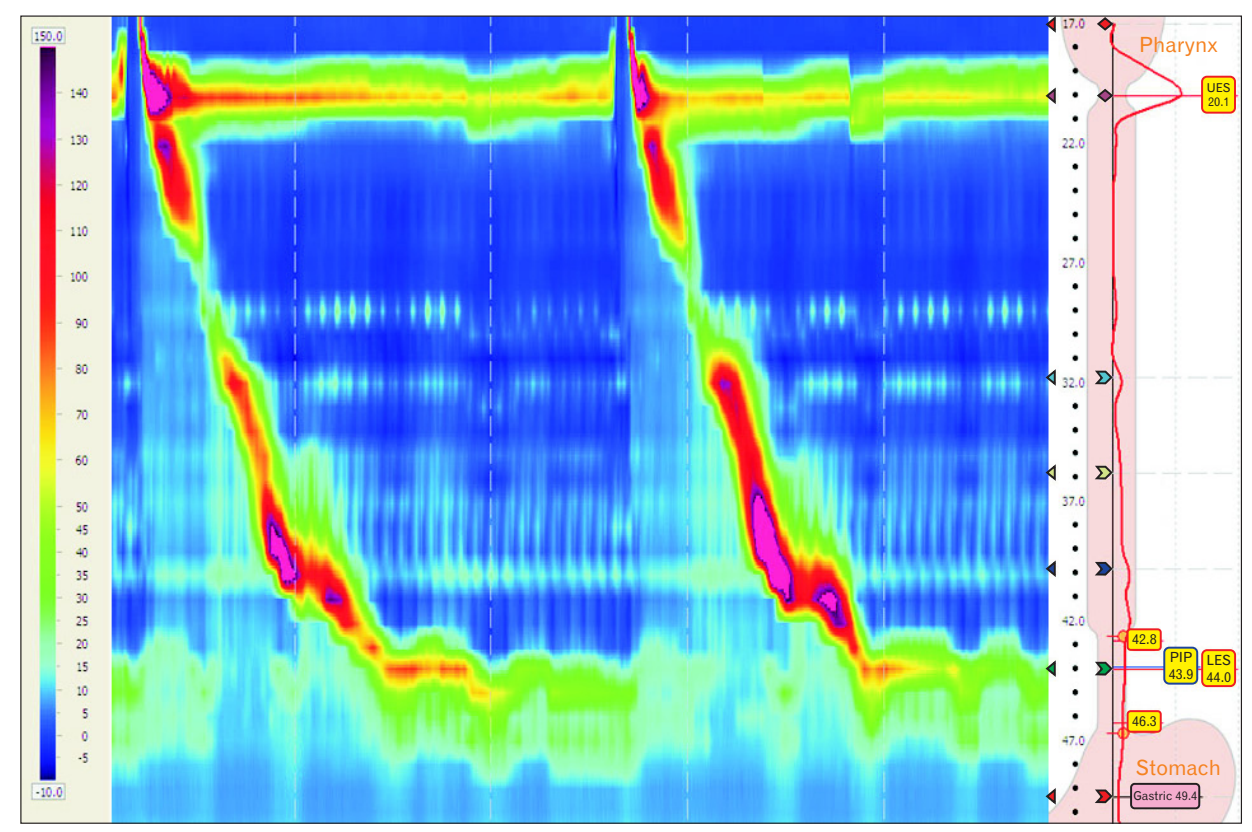

Figure 1. The intraluminal pressure is viewed as a continuum with isocoloric regions indicating isobaric conditions among sensors, permitting the assessment of propagation velocity, contraction vigor, and lower esophageal sphincter (LES) relaxation all at the same time. The markers for the upper esophageal sphincter (UES), LES, and stomach are correctly placed. sors. As a result, manometry recordings could thenceforth be displayed as a continuous pressure plot in which pressure amplitude is expressed as colors similarly to an altitude map (Fig. 1), rather than the previously displayed 2-D line tracing format. ${ }^{7.8}$ In these so-called esophageal pressure topography (EPT) plots, with time on the $\mathrm{x}$-axis and esophageal position on the $\mathrm{y}$-axis, warmer colors represent high pressures and colder colors represent low pressures. ${ }^{7}$

It was inevitable that the introduction of EPT led to new metrics and parameters. This strengthened the need to reassess the classification scheme, which was originally developed for conventional manometry measurements. ${ }^{9}$ In 2008, the first official classification system for EPT, the Chicago classification, was developed after several studies in healthy volunteers and patients. ${ }^{10-14} \mathrm{~A}$ second iteration was published in 2012, ${ }^{15}$ which was most recently updated in $2015 .{ }^{16} \mathrm{HRM}$ has become increasingly important and is now the new worldwide standard for the clinical evaluation of esophageal motility disorders. The implementation of HRM is a major improvement compared to conventional manometry. In this review we discuss how HRM changed the field of esophageal motility disorders.

\section{Technical Aspects of High-resolution Manometry}

Two different types of manometry systems can be distinguished, namely water-perfused versus solid state catheters. Every system has its own advantages and disadvantages and different normal values. ${ }^{17-21}$ In short, an HRM study consists of 2 phases: analysis during swallows and during rest. Before or after administering ten $5 \mathrm{~mL}$ water swallows to the patient, a "resting" landmark recording is measured during an episode in which the patient does not swallow and breathe normally. In this landmark episode, markers for the level of the UES, the upper and lower border of the LES and the stomach are placed (Fig. 1). The software measures the LES resting pressure in this landmark recording window.

\section{Interpretation of Data}

According to the Chicago classification, the analysis and interpretation of HRM is performed in 2 steps following a hierarchical flow-chart (Fig. 2). First, the individual swallow patterns are evaluated and classified. The distal contractile integral (DCI) is measured as a multiplication of the amplitude, length and duration of the contraction $(\mathrm{mmHg} \cdot \mathrm{cm} \cdot \mathrm{sec})$ and the distal latency is measured as the time between UES relaxation and the deceleration point of the contractile front of the contractile wave. For each swallow, the contraction is determined to be peristaltic, simultaneous, or failed (DCI $<100 \mathrm{mmHg} \cdot \mathrm{cm} \cdot \mathrm{sec}$ ). In addition, the peristaltic contractions are determined to be weak (DCI 100-450 $\mathrm{mmHg} \cdot \mathrm{cm} \cdot \mathrm{sec}$ ), hypercontractile (DCI $\geq 8000 \mathrm{mmHg} \cdot \mathrm{cm} \cdot \mathrm{sec}$ ), premature (distal latency $<4.5 \mathrm{sec}$ ), fragmented (peristaltic break $>5 \mathrm{~cm}$ ), or normal.

Based on the information from the individual swallows, a hierarchical categorization of motility disorders is made. First the LES 
The chicago classification v3.0

Hierarchical analysis

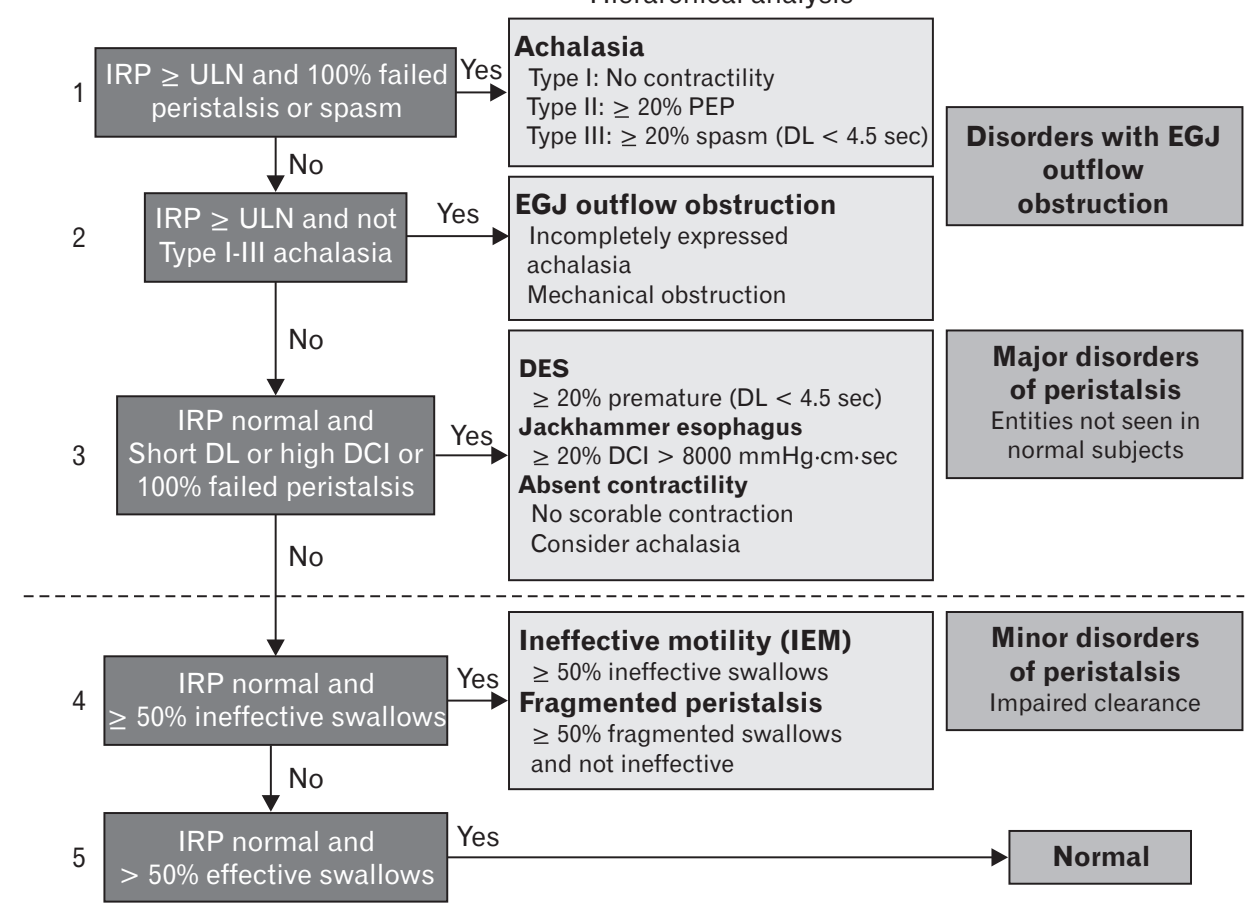

Figure 2. Hierarchical flow-chart from the Chicago classification version 3.0. IRP, integrated relaxation pressure; ULN, upper limit of normal; DL, distal latency; DCI, distal contractile integral; PEP, panesophageal pressurization; EGJ, esophagogastric junction; DES, distal esophageal spasm. Adapted from Kahrilas et $\mathrm{al}^{16}$ with permission of Wiley. function, and subsequently the esophageal pressure patterns are used to classify the patient and make a diagnosis. ${ }^{16}$ The hierarchical flow-chart has 4 groups: (1) incomplete LES relaxation (achalasia or esophagogastric junction outflow obstruction); (2) major motility disorders, ie, disorders never seen in asymptomatic controls (absent contractility, distal esophageal spasm, and hypercontractile esophagus); (3) minor motility disorders, ie, findings that can be found in asymptomatic individuals (ineffective esophageal motility or fragmented peristalsis); and (4) normal esophageal motility.

\section{Advantages of High-resolution Manometry -}

HRM offers several advantages over conventional manometry. First, the visual display simplifies the positioning of the catheter and reduces the chance that a catheter is positioned incorrectly. ${ }^{22}$ Also, the pressure pattern of the entire esophagus is assessed simultaneously, eliminating the need for repositioning or repetitive pullthrough maneuvers. As a result, HRM is easier to perform with a significantly shorter procedure time than conventional manometry. $^{23,24}$

Second, the shorter intervals between the pressure sensors ensures that no relevant information gets lost, and the high resolution leads to a greater reproducibility. ${ }^{24}$ This provides a more detailed assessment of pressure measurements, supposedly enabling a more objective evaluation of esophageal motility disorders. ${ }^{7,911,22,25}$ Yet, HRM and conventional manometry have never been compared directly.

Last, the standardized display method and additional computer algorithms enable a more objective, as well as a more intuitive, interpretation, which is easier to learn than the interpretation of conventional line tracings. This provides a steep learning curve for both experts and trainees. ${ }^{23,26}$ Also, the interobserver ${ }^{27}$ and intraobserver ${ }^{28}$ agreement is better in HRM than in conventional manometry. In a study comparing diagnostic accuracy and interobserver variability among interpreters with and without experience, HRM provided superior diagnostic accuracy compared to conventional manometry. ${ }^{29}$

\section{Clinical Application of High-resolution Manometry in Esophageal Motility}

\section{Achalasia}

The introduction of HRM led to a large series of new research projects investigating the best way of analyzing and quantifying LES relaxation and peristalsis, which are both crucial elements in the evaluation of achalasia. Currently, the most used way of measuring the LES relaxation resting pressure was introduced by Ghosh et al. ${ }^{14}$ They defined the 4-second integrated relaxation pressure 
(IRP-4): the median LES pressure related to the gastric pressure during the 4 seconds of lowest LES pressure within a timeframe of 10 seconds starting from the moment of UES relaxation. ${ }^{14}$ Using the integrated relaxation pressure (IRP), achalasia can be defined more precisely than with conventional manometry. ${ }^{13,14}$ This makes it easier to distinguish artefacts from real impaired relaxation during swallowing.

Moreover, with the advent of HRM, different pressure patterns in achalasia were recognized. In 2008, Pandolfino et al. ${ }^{30}$ described 3 distinct types of achalasia. All 3 types are characterized by incomplete LES relaxation, but they differ in pressurization patterns and presence of spastic contractions. ${ }^{16,31}$ Type I is called classic achalasia (absent pressurization), type II is achalasia with pressurization (bolus compression causing panesophageal pressurization) and type III is spastic achalasia (premature contractions with high amplitude). ${ }^{24}$

This new subclassification has shown to be helpful in the prediction of treatment response. Several studies show differences in treatment response between the 3 achalasia subtypes. ${ }^{11,25,32-34}$ All studies uniformly observe the best treatment response in patients with type II achalasia and the worst response in patients with type III achalasia. Treatment effects are variable among the 3 subtypes. This accounts for all different treatment modalities, suggesting that achalasia subtype can serve as a criterion for the optimal treatment in different patients. ${ }^{25,32}$

\section{Esophagogastric Junction Outflow Obstruction}

Using HRM, a patient group was discovered with incomplete LES relaxation combined with preserved peristalsis, therefore not meeting achalasia criteria. ${ }^{35}$ This disorder used to be called LES dysrelaxation when detected with conventional manometry. In the first HRM classification it was called a functional obstruction. After demonstration of an elevated intrabolus pressure, it was called an esophagogastric junction (EGJ) outflow obstruction. ${ }^{16,35}$ It has been reported to be a result of an infiltrative disease, or a variant or incomplete onset of achalasia. ${ }^{36,37}$ However, EGJ outflow obstruction is a clinically unclear disorder. In some patients, the symptoms are similar to achalasia with good effect of achalasia treatment, whereas in other patients the symptoms disappear spontaneously or are not related to an outflow obstruction. ${ }^{36,37}$ The current advice is to use subsequent diagnostic tests to identify patients with "true" outflow obstruction and stasis and distinguish them from patients with a coincidental finding of high IRP. Patients with true outflow obstruction should be treated with achalasia therapy. Although evidence is not from controlled studies, if it is uncertain of what direction the case is developing, one could opt for botox injections in the LES and repeat testing 12 months later in order to see if achalasia has developed.

\section{Absent Contractility}

Absent contractility is a rare finding and diagnosed in patients with a normal IRP and $100 \%$ failed peristalsis. Absent contractility can be seen in patients with systemic sclerosis and predisposes patients to gastroesophageal reflux disease. Absent contractility is clinically important in patients that are considered for fundoplication or gastric bypass surgery. In patients with absent contractility, these surgical interventions are contra-indicated because a higher chance of post-surgical dysphagia is expected. Nonetheless, in healthy subjects, the clinical significance of absent contractility and the contribution to dysphagia and heartburn is not completely clear. One should be aware that absent contractility is not similar to absent pressurization. HRM can differentiate between these two. ${ }^{24}$

In conventional manometry, absent peristalsis was sometimes erroneously diagnosed in achalasia patients, because shortening of the esophagus could mimic LES-relaxation as the LES would move away from the sensor resulting in a measurement of a decrease in pressure which could be interpreted as a relaxation. The false diagnosis of LES relaxation due to the LES moving proximally during swallowing was later called pseudorelaxation. After introduction of HRM with its continuous pressure plot, it was seen that pseudorelaxation could even happen using the sleeve sensor, for example during extreme esophageal shortening in type III achalasia. With the introduction of HRM, pseudorelaxation was dispelled. This gives HRM a higher sensitivity to distinguish achalasia from absent contractility, and to distinguish spastic achalasia from distal esophageal spasm.

\section{Distal Esophageal Spasm}

Distal esophageal spasm, also known as diffuse esophageal spasm is diagnosed when premature contractions are seen. ${ }^{38}$ This means that the time between the onset of the UES relaxation and the arrival of the peristaltic wave in the distal esophagus (distal latency) is too short. It was always thought that rapid (simultaneous) and premature contractions were the same. Later, it was shown that a simultaneous esophageal pressure rise is not necessarily caused by a simultaneous contraction, but can also be caused by pressurization. ${ }^{9}$ The contractile front velocity, defining rapid contractions, is a nonspecific and unreliable measure, and can be variable within one subject. $^{39}$

After studying patients with premature rapid contractions and 
patients with rapid contractions with normal latency, it was shown that premature rapid contractions correlated better with symptoms and an ultimate diagnosis of distal esophageal spasm or achalasia. Importantly, rapid contractions with normal latency did not always have achalasia-like symptoms and no final diagnosis of spasm. ${ }^{16,38}$ For this reason, in the current Chicago classification, distal esophageal spasm is defined as $\geq 20 \%$ of swallows with reduced distal latency, thus premature contractions. Using distal latency as the most important measure for distal esophageal spasm is more reliable, and correlates better with dysphagia and chest pain. ${ }^{39}$

\section{Jackhammer (Hypercontractile Esophagus)}

In conventional manometry as well as early versions of the Chicago classification, several distinct diagnoses existed for contractions with elevated peristaltic wave amplitude such as nutcracker esophagus, hypertensive peristalsis, and hypercontractile esophagus. However, isolated elevated peristaltic wave amplitude is usually not associated with symptoms and can be found in healthy subjects as well. ${ }^{40}$ For this reason, a new parameter was introduced to measure the vigor of peristalsis: the DCI. This is a multiplication of length, duration, and amplitude of contractions. ${ }^{11}$ At first, a DCI $\geq 5000 \mathrm{mmHg} \cdot \mathrm{cm} \cdot \mathrm{sec}$ was defined to be abnormal. However, asymptomatic controls sometimes have individual swallows with a DCI $\geq 5000 \mathrm{mmHg} \cdot \mathrm{cm} \cdot \mathrm{sec}$, but almost never with a DCI $\geq$ $8000 \mathrm{mmHg} \cdot \mathrm{cm} \cdot \mathrm{sec}$, while symptomatic patients sometimes do have swallows with a DCI $\geq 8000 \mathrm{mmHg} \cdot \mathrm{cm} \cdot \mathrm{sec}$ and in order to reach this DCI level these contractions usually also have spastic characteristics such as multipeaks, repetitive patterns and short distal latency. ${ }^{40}$ A DCI $\geq 8000 \mathrm{mmHg} \cdot \mathrm{cm} \cdot \mathrm{sec}$ was found to be associated with chest pain and dysphagia and with positive response to achalasia treatment, thus clinically relevant. ${ }^{10,11,31}$ The term Jackhammer esophagus was chosen because these patients more often had strong multipeaked contractions. ${ }^{40}$ Multipeaked contractions however, were not associated with more symptoms or a better treatment response.

For this reason, Jackhammer esophagus was defined as at least two swallows with a DCI $\geq 8000 \mathrm{mmHg} \cdot \mathrm{cm} \cdot \mathrm{sec}$, irrespective of the presence of multipeaked contractions. Nutcracker esophagus and hypertensive peristalsis have been replaced by the term Jackhammer esophagus, also known as hypercontractile esophagus. ${ }^{16}$

\section{Ineffective Esophageal Motility}

Low DCI was found to be a predictor of ineffective or failed peristalsis and is thus incorporated into the Chicago classification. Ineffective esophageal motility is diagnosed when $>50 \%$ of swal- lows is ineffective, that is either failed (DCI $<100 \mathrm{mmHg} \cdot \mathrm{cm} \cdot \mathrm{sec}$ ) or weak (DCI 100-450 $\mathrm{mmHg} \cdot \mathrm{cm} \cdot \mathrm{sec}$ ). Ineffective esophageal motility is well-known from conventional manometry. It is often accompanied by a low LES pressure. ${ }^{41}$ Ineffective esophageal motility and a hiatal hernia or low LES pressure were found to be more prevalent in patients with gastroesophageal reflux disesase. However, the predictive value of these findings to predict reflux disease is insufficient. ${ }^{42}$ As with absent contractility, it is only clinically important in patients in evaluation for antireflux surgery.

Conventional manometry was not able to discriminate between the pressure contributions of LES and the diaphragm, due to low spatial resolution. ${ }^{24}$ In HRM two separate high pressure zones were visible in some patients. ${ }^{8} \mathrm{HRM}$ was found to be very reliable in detecting a hiatal hernia. ${ }^{43}$ Eventually, three degrees of hiatal hernia were distinguished depending on the spatial overlap between LES and diaphragmatic pinch. ${ }^{44}$

To some extent, conventional manometry is able to predict the effect of peristalsis on volume clearance. ${ }^{45}$ It was thought that HRM would be better in predicting volume clearance. Unfortunately, also in HRM, the relation between abnormal peristalsis and failed bolus transport is limited. ${ }^{46}$ In other words, the more precise measuring method of HRM is still not resulting in a better correlation between motility, bolus transport and symptoms.

\section{Fragmented Peristalsis}

Because HRM allows to visualize the contractile activity of the entire esophagus, it offers detection of areas in the peristaltic wave with lower amplitude, so called "pressure breaks". The clinical relevance of these pressure breaks is uncertain, but is has been suggested these are associated with bolus escape in the esophagus with swallowing. ${ }^{47}$ As with failed bolus transport, pressure breaks are also common in healthy controls without dysphagia. ${ }^{48}$ Furthermore, the size of the break is not predictive of stasis on barium esophagography. ${ }^{46}$ However, large breaks are associated with more severe gastroesophageal reflux disease. ${ }^{49}$ Large breaks, low LES pressure and failed peristalsis are more often found in gastroesophageal reflux disesase patients. Nonetheless, they are of negligible predictive value in diagnosing reflux disease. ${ }^{42}$

Studies using HRM and intraluminal impedance showed an association between small breaks and impaired bolus transport. ${ }^{47,50}$ Both small and large breaks are more often seen in patients, but they are also sometimes seen in controls. ${ }^{47}$ As with ineffective motility and absent contractility, fragmented peristalsis also has an unclear clinical significance in healthy subjects as the contribution to symptom generation remains unclear. 


\section{Normal Esophageal Motility}

As mentioned before, HRM is more sensitive and accurate than conventional manometry. With the evolution of HRM, minor deficiencies in peristalsis, such as pressure breaks, became visible. One study converted HRM data into line plots (like conventional manometry) and correlated the diagnosis of ineffective esophageal motility with colorplot findings. ${ }^{51}$ As expected, using colorplots, more abnormalities (ineffective or fragmented peristalsis) were diagnosed than using line plots. Hypomotile abnormalities were found in more than $35 \%$ of studies classified as normal.

To some extent this shows that HRM invites over-interpretation of the measurement, leading to less patients with normal esophageal motility. Although these minor motor disorders became measurable, they are generally found to be clinically irrelevant, having a good prognosis. ${ }^{52}$

\section{Limitations of High-resolution Manometry}

Some limitations of HRM should be mentioned. First of all, thus far, despite more details on esophageal motility, HRM provides no better explanation of non-obstructive dysphagia. Second, there is insufficient knowledge about how technical and patient specific factors influence results of HRM measurements. ${ }^{21}$ Besides the fact that each HRM system has its own normative values, catheter diameter, pressure drift, ${ }^{53}$ spatial resolution, ${ }^{54}$ age, obesity, ethnicity, body position, and esophageal length are known to influence HRM measurements. ${ }^{21}$ Last, HRM is more expensive than conventional manometry, both in equipment and maintenance costs. A limitation of the Chicago classification should also be mentioned. While the innovation of HRM and the subsequent evolution of the classification improved our diagnostic abilities, a number of abnormalities or diagnoses are not incorporated in the Chicago classification. For example UES abnormalities and post-surgical problems are not classified. A previous study calculated that $32 \%$ of their patients undergoing HRM had abnormalities that were not described in the Chicago classification. ${ }^{55}$

\section{Future Directions}

HRM will continue to undergo further development. Several studies are carried out to find new applications. The current Chicago classification is based on analyzing $5 \mathrm{~mL}$ water swallows, and cannot be applied to viscous or solid bolus swallows. Several studies are trying to find a clinical value of viscous or solid swallows. ${ }^{56}$ On the other hand, solid swallows are also often abnormal in healthy subjects and are difficult to interpret. Also, multiple rapid swallows are currently being investigated. It is hypothesized that panesophageal pressurization during multiple rapid swallows is a sign for true stasis, justifying a diagnosis of achalasia and EGJ outflow obstruction. Future studies will clarify whether these esophageal stress tests add value or just confusion.

\section{Conclusion}

Esophageal HRM is the gold standard for diagnosing and evaluating esophageal motility disorders. It provides an easier to perform, more detailed measurement, throughout the entire length of the esophagus, with a clear-cut visual display of recordings. This improves the interpretation of esophageal motor function. More specifically: LES dysrelaxation, hiatal hernia, contraction velocity, and contraction vigor became better evaluable. The most important clinical application is the subcategorization of achalasia correlating with treatment response, probably the first step in a personalized treatment.

\section{Financial support: None.}

Conflicts of interest: Albert J Bredenoord received research funding from Endostim, Medical Measurement Systems, Danone and Given and received speaker and/or consulting fees from MMS, Astellas, AstraZeneca and Almirall.

\section{References}

1. Butin JW, Olsen AM, Moersch HJ, Code CF. A study of esophageal pressures in normal persons and patients with cardiospasm. Gastroenterology 1953;23:278-293.

2. Stef JJ, Dodds WJ, Hogan WJ, Linehan JH, Stewart ET. Intraluminal esophageal manometry: an analysis of variables affecting recording fidelity of peristaltic pressures. Gastroenterology 1974;67:221-230.

3. Dent J. A new technique for continuous sphincter pressure measurement. Gastroenterology 1976;71:263-267.

4. Arndorfer RC, Stef JJ, Dodds WJ, Linehan JH, Hogan WJ. Improved infusion system for intraluminal esophageal manometry. Gastroenterology 1977;73:23-27.

5. Clouse RE, Parks T, Haroian L, Zakko SF. Development and clinical validation of a solid-state high-resolution pressure measurement system for simplified and consistent esophageal manometry. Am J Gastroenterol 2003;98:S32-S33

6. Hebbard GS, Feinle C, Kunz P, et al. Technical aspects of high-resolution perfusion manometry - an underwater zero improves accuracy of mea- 
surement of catheter offset and transducer drift. Gastroenterology 1997; 112:A745

7. Clouse RE, Staiano A. Topography of the esophageal peristaltic pressure wave. Am J Physiol 1991;261(4 Pt 1):G677-G684.

8. Clouse RE, Staiano A, Alrakawi A, Haroian L. Application of topographical methods to clinical esophageal manometry. Am J Gastroenterol 2000;95:2720-2730.

9. Fox M, Bredenoord AJ. Oesophageal high-resolution manometry: moving from research into clinical practice. Gut 2008;57:405-423.

10. Kahrilas PJ, Ghosh SK, Pandolfino JE. Esophageal motility disorders in terms of pressure topography: the Chicago classification. J Clin Gastroenterol 2008;42:627-635.

11. Pandolfino JE, Ghosh SK, Rice J, Clarke JO, Kwiatek MA, Kahrilas PJ. Classifying esophageal motility by pressure topography characteristics: a study of 400 patients and 75 controls. Am J Gastroenterol 2008;103:2737.

12. Ghosh SK, Pandolfino JE, Zhang Q, Jarosz A, Shah N, Kahrilas PJ. Quantifying esophageal peristalsis with high-resolution manometry: a study of 75 asymptomatic volunteers. Am J Physiol Gastrointest Liver Physiol 2006;290:G988-G997.

13. Pandolfino JE, Ghosh SK, Zhang Q, Jarosz A, Shah N, Kahrilas PJ. Quantifying EGJ morphology and relaxation with high-resolution manometry: a study of 75 asymptomatic volunteers. Am J Physiol Gastrointest Liver Physiol 2006;290:G1033-G1040.

14. Ghosh SK, Pandolfino JE, Rice J, Clarke JO, Kwiatek M, Kahrilas PJ. Impaired deglutitive EGJ relaxation in clinical esophageal manometry: a quantitative analysis of 400 patients and 75 controls. Am J Physiol Gastrointest Liver Physiol 2007;293:G878-G885.

15. Bredenoord AJ, Fox M, Kahrilas PJ, et al. Chicago classification criteria of esophageal motility disorders defined in high resolution esophageal pressure topography. Neurogastroenterol Motil 2012;24(suppl 1):57-65.

16. Kahrilas PJ, Bredenoord AJ, Fox M, et al. The Chicago classification of esophageal motility disorders, v3.0. Neurogastroenterol Motil 2015;27:160-174.

17. Niebisch S, Wilshire CL, Peters JH. Systematic analysis of esophageal pressure topography in high-resolution manometry of 68 normal volunteers. Dis Esophagus 2013;26:651-660.

18. Weijenborg PW, Kessing BF, Smout AJ, Bredenoord AJ. Normal values for solid-state esophageal high-resolution manometry in a European population; an overview of all current metrics. Neurogastroenterol Motil 2014;26:654-659.

19. Sweis R, Anggiansah A, Wong T, Kaufman E, Obrecht S, Fox M. Normative values and inter-observer agreement for liquid and solid bolus swallows in upright and supine positions as assessed by esophageal highresolution manometry. Neurogastroenterol Motil 2011;23:509-e198.

20. Bogte A, Bredenoord AJ, Oors J, Siersema PD, Smout AJ. Normal values for esophageal high-resolution manometry. Neurogastroenterol Motil 2013;25:762-e579.

21. Herregods TV, Roman S, Kahrilas PJ, Smout AJ, Bredenoord AJ. Normative values in esophageal high-resolution manometry. Neurogastroenterol Motil 2015;27:175-187.

22. Fox M, Hebbard G, Janiak P, et al. High-resolution manometry predicts the success of oesophageal bolus transport and identifies clinically important abnormalities not detected by conventional manometry. Neurogastroenterol Motil 2004;16:533-542.

23. Grubel C, Hiscock R, Hebbard G. Value of spatiotemporal representation of manometric data. Clin Gastroenterol Hepatol 2008;6:525-530.

24. Bansal A, Kahrilas PJ. Has high-resolution manometry changed the approach to esophageal motility disorders? Curr Opin Gastroenterol 2010;26:344-351.

25. Lee JY, Kim N, Kim SE, et al. Clinical characteristics and treatment outcomes of 3 subtypes of achalasia according to the Chicago classification in a tertiary institute in Korea. J Neurogastroenterol Motil 2013;19:485494.

26. Soudagar AS, Sayuk GS, Gyawali CP. Learners favour high resolution oesophageal manometry with better diagnostic accuracy over conventional line tracings. Gut 2012;61:798-803.

27. Fox MR, Pandolfino JE, Sweis R, et al. Inter-observer agreement for diagnostic classification of esophageal motility disorders defined in highresolution manometry. Dis Esophagus Published Online First: 2 Sep 2014. doi: 10.1111/dote.12278.

28. Bogte A, Bredenoord AJ, Oors J, Siersema PD, Smout AJ. Reproducibility of esophageal high-resolution manometry. Neurogastroenterol Motil 2011;23:e271-e276.

29. Carlson DA, Ravi K, Kahrilas PJ, et al. Diagnosis of esophageal motility disorders: esophageal pressure topography vs. conventional line tracing. Am J Gastroenterol 2015;110:967-977.

30. Pandolfino JE, Kwiatek MA, Nealis T, Bulsiewicz W, Post J, Kahrilas PJ. Achalasia: a new clinically relevant classification by high-resolution manometry. Gastroenterology 2008;135:1526-1533.

31. Pandolfino JE, Fox MR, Bredenoord AJ, Kahrilas PJ. High-resolution manometry in clinical practice: utilizing pressure topography to classify oesophageal motility abnormalities. Neurogastroenterol Motil 2009;21:796-806.

32. Rohof WO, Salvador R, Annese V, et al. Outcomes of treatment for achalasia depend on manometric subtype. Gastroenterology 2013;144:718725.

33. Pratap N, Kalapala R, Darisetty S, et al. Achalasia cardia subtyping by high-resolution manometry predicts the therapeutic outcome of pneumatic balloon dilatation. J Neurogastroenterol Motil 2011;17:48-53.

34. Salvador R, Costantini M, Zaninotto G, et al. The preoperative manometric pattern predicts the outcome of surgical treatment for esophageal achalasia. J Gastrointest Surg 2010;14:1635-1645.

35. Carlson DA, Pandolfino JE. High-resolution manometry and esophageal pressure topography: filling the gaps of convention manometry. Gastroenterol Clin North Am 2013;42:1-15.

36. Scherer JR, Kwiatek MA, Soper NJ, Pandolfino JE, Kahrilas PJ. Functional esophagogastric junction obstruction with intact peristalsis: a heterogeneous syndrome sometimes akin to achalasia. J Gastrointest Surg 2009;13:2219-2225.

37. van Hoeij FB, Smout AJ, Bredenoord AJ. Characterization of idiopathic esophagogastric junction outflow obstruction. Neurogastroenterol Motil 2015;27:1310-1316

38. Achem SR. Diffuse esophageal spasm in the era of high-resolution ma- 
nometry. Gastroenterol Hepatol 2014;10:130-133.

39. Pandolfino JE, Roman S, Carlson D, et al. Distal esophageal spasm in high-resolution esophageal pressure topography: defining clinical phenotypes. Gastroenterology 2011;141:469-475.

40. Roman S, Pandolfino JE, Chen J, Boris L, Luger D, Kahrilas PJ. Phenotypes and clinical context of hypercontractility in high-resolution esophageal pressure topography (EPT). Am J Gastroenterol 2012;107:37-45.

41. Spechler SJ, Castell DO. Classification of oesophageal motility abnormalities. Gut 2001;49:145-151.

42. van Hoeij FB, Smout AJ, Bredenoord AJ. Predictive value of routine esophageal high-resolution manometry for gastro-esophageal reflux disease. Neurogastroenterol Motil 2015;27:963-970.

43. Weijenborg PW, van Hoeij FB, Smout AJ, Bredenoord AJ. Accuracy of hiatal hernia detection with esophageal high-resolution manometry. Neurogastroenterol Motil 2015;27:293-299.

44. Pandolfino JE, Kwiatek MA, Ho K, Scherer JR, Kahrilas PJ. Unique features of esophagogastric junction pressure topography in hiatus hernia patients with dysphagia. Surgery 2010;147:57-64.

45. Kahrilas PJ, Dodds WJ, Hogan WJ. Effect of peristaltic dysfunction on esophageal volume clearance. Gastroenterology 1988;94:73-80.

46. Bogte A, Bredenoord AJ, Oors J, Siersema PD, Smout AJ. Sensation of stasis is poorly correlated with impaired esophageal bolus transport. Neurogastroenterol Motil 2014;26:538-545.

47. Roman S, Lin Z, Kwiatek MA, Pandolfino JE, Kahrilas PJ. Weak peristalsis in esophageal pressure topography: classification and association with dysphagia. Am J Gastroenterol 2011;106:349-356.

48. Kumar N, Porter RF, Chanin JM, Gyawali CP. Analysis of intersegmental trough and proximal latency of smooth muscle contraction using highresolution esophageal manometry. J Clin Gastroenterol 2012;46:375-381.
49. Ribolsi M, Balestrieri P, Emerenziani S, Guarino MP, Cicala M. Weak peristalsis with large breaks is associated with higher acid exposure and delayed reflux clearance in the supine position in GERD patients. Am J Gastroenterol 2014;109:46-51.

50. Bulsiewicz WJ, Kahrilas PJ, Kwiatek MA, Ghosh SK, Meek A, Pandolfino JE. Esophageal pressure topography criteria indicative of incomplete bolus clearance: a study using high-resolution impedance manometry. Am J Gastroenterol 2009;104:2721-2728.

51. Xiao Y, Kahrilas PJ, Kwasny MJ, et al. High-resolution manometry correlates of ineffective esophageal motility. Am J Gastroenterol 2012;107: 1647-1654.

52. Ravi K, Friesen L, Issaka R, Kahrilas PJ, Pandolfino JE. Long-term outcomes of patients with normal or minor motor function abnormalities detected by high-resolution esophageal manometry. Clin Gastroenterol Hepatol 2015;13:1416-1423.

53. Babaei A, Lin EC, Szabo A, Massey BT. Determinants of pressure drift in Manoscan ${ }^{\mathrm{TM}}$ esophageal high-resolution manometry system. Neurogastroenterol Motil 2015;27:277-284.

54. De Schepper HU, Kessing BF, Weijenborg PW, Oors JM, Smout AJ, Bredenoord AJ. Impact of spatial resolution on results of esophageal high-resolution manometry. Neurogastroenterol Motil 2014;26:922-928.

55. Wang YT, Yazaki E, Sifrim D. High-resolution manometry: esophageal disorders not addressed by the "Chicago classification". J Neurogastroenterol Motil 2012;18:365-372.

56. Wang YT, Tai LF, Yazaki E, et al. Investigation of dysphagia after antireflux surgery by high-resolution manometry: impact of multiple water swallows and a solid test meal on diagnosis, management, and clinical outcome. Clin Gastroenterol Hepatol 2015;13:1575-1583. 